\title{
Mobile Game Based Chemical Bond Learning Application
}

\author{
Kholid Fathoni, Rizky Yuniar Hakkun, Wildan Andaru \\ Politeknik Elektronika Negeri Surabaya \\ Email:kholid@pens.ac.id, rizky@pens.ac.id, andaruwildan@gmail.com
}

\begin{abstract}
Mobile game technology is growing rapidly and this is directly proportional to the increasing number of mobile games in circulation. The growing market of the mobile game industry is not accompanied by the number of games that have educative content in them. The challenging, fun, and addictive nature of the game has a negative impact if no educational content is provided. Therefore, educational content needs to be present in a game so that the game can have a positive impact on the players. This research makes a chemical educational game to study chemical bonding material that aims as an interactive learning media for students and the general public. This game is made based on mobile with $2 D$ characters consisting of 5 levels. Level 1 contains material for salt compounds, level 2 contains material for acid compounds, level 3, 4 and 5 contains material for basic compounds. The results of this game trial show that all the features of this game application run well, can be run on several smartphones, and most users from 20 audiences stated that this game is comfortable and easy to use.
\end{abstract}

\section{Keywords : Chemical Bond, Learning, Game, Mobile, 2D Characters}

\section{Introduction}

Education is a primary need for humans to live life. The United Nations through its educational institutions (UNESCO) states two relevant educational principles, firstly educators must understand and implement the four pillars of learning to know, learning to do, learning to live together (learning to do) life together) and learning to be yourself (learning to be), second learning for a lifetime (life long learning) [1]. National Education aims to develop self-potential and form a character that has noble character to build a dignified national civilization [2]. Learning is a process in which humans change their behavior because of the life experiences they have experienced [3]. This can be related to the statement of the Greek philosophical expert, Plato, which is related to education. According to Plato, education causes the character of people to be better and good people will have noble behavior [4]. Learning is the result of experiences that contain several stimuli and responses; humans learn from the environment (outside of themselves) that is internalized through a stimulus that causes several emotional responses [3].

The process of human learning starts from children. Children have different characteristics from adults in attitude and behavior including learning. How to learn children have different characteristics with adults. Teachers and parents should understand the characteristics of children's learning and make it a reference in planning and implementing learning. Characteristics of children's learning [5], namely:

1. children learn through play,

2. children learn by building knowledge,

3. children learn naturally,

4. children learn best if what is learned considers all aspects of development, meaningful, interesting, and functional.

The character of the way to learn the 4th child shows that learning for children must be interesting. Interactive methods will make learning more effective and interesting. A teacher must have creativity in managing the learning process 
in order to be able to present enjoyable learning [5]. In the learning strategy, when the teacher teaches not all students want to learn; but when students are many active and moving, this is what is said that students are learning [6].

Currently many methods or technologies are used to attract children to be active in the educational process starting from the use of picture books and interactive videos. Some games that are used for learning include: mobile games for learning historical figures[7], virtual reality based games for learning heroic history[8], games for learning biology[9], and so on. However, these methods are now considered too general and the technology is not the most recent technology. The development of multimedia technology has caused a variety of learning methods and media to increase. Actually games that have educative content have been developed but not many are reaping success in the market. Educational games with chemical themes circulating in mobile application stores such as Play Store or App Store are still largely in the form of questions and answers and puzzles about chemistry and the game's flow is limited to how the player has to solve the questions given. This causes the loss of one of the benefits of the game itself, namely as a medium of entertainment.

Chemical bonding material in high school chemistry subjects is one of the materials that is difficult to learn. Broadly speaking, in chemical bonds there are ionic bonds and covalent bonds. The nature of atoms in chemical bonds that attract each other makes this material can be raised to be an interesting educational game. By combining educational content about chemical bonds and physics engines, it makes an educational game to be fun to play.

\section{Related Works}

Some research on chemical education games has been done before. First, research with the title "Chomical: Game Tower Defense by Applying Chemical Experiments Using the LibGDX Framework" made by Annisa U Istighotsah from the Faculty of Information Technology, Institute of Technology, Ten November. The rules of the game are that players must carry out chemical experiments to make bullets. The bullet is used to attack the enemy in a battle which is a tower defense game. By defeating enemies, players can find new chemicals for further experiments. Development is carried out with the libGDX framework. The game is developed with the Java programming language and code implementation is carried out in the Eclipse software development environment[10].

Then the second study with the title "Brainchemist: Mobile game as a medium for learning chemistry high school I MA on acid-base material, buffer solution, and salt hydrolysis" made by Yogo Dwi Prasetyo from Yogyakarta State University in the form of an Android-based chemistry learning media. Application made in the form of a quiz where ready a set of games consists of 10 questions. This application is equipped with material, instructions, scores, and does not contain animations and moving images[11].

Both studies have a similar case, namely creating a chemical educational game as an interactive learning tool. The purpose of this research is to create an interactive learning media through interesting games based on chemical bonding material that can help users learn compounds in chemistry. Games are packaged in the form of arcade games that are played on smartphones.

\section{Method}

This game uses the theory of chemical bonds as a rule of play. Chemical bonding 
is a physical process that is responsible for the interaction of attractive forces between two atoms or molecules that causes a diatomic or polyatomic compound to become stable[12]. Electrons that surround the nucleus of negatively charged atoms and protons contained in the nucleus of positively charged atoms, given the opposite charge will attract each other, then the two atoms close to each other will form bonds.

For example in table salt (sodium chloride). When sodium (Na) and chlorine $(\mathrm{Cl})$ combine, sodium atoms lose electrons, forming cations $(\mathrm{Na}+)$, while chlorine atoms accept electrons to form anions $(\mathrm{Cl}-$ ). These ions then attract each other in a ratio of 1: 1 to form sodium chloride.

\section{System Design}

There are some menus: play games, shop, tutorial, about and quit. When the application is opened, the screen will be directed to the main menu display of the game. There are 5 sub-menu choices in the main menu, which are play game, shop, tutorial, about, and quit. Play Games menu is used to start playing the game. When the game is finished, the user is directed to the game over display which has the option to repeat the game if it fails to fulfill the given mission or continue to the next stage if it successfully fulfills the mission.Shop contains features to upgrade or buy items to customize gameplay. Players make purchases using the star obtained by playing this game.Tutorial is the page that contains instructions on how to play the game Shoot The Ion so that ordinary players can play this game. About is the page that contains the profiles of the game and the developer. Quit / Back Key is used to exit the application. The details of the menus are shown below.

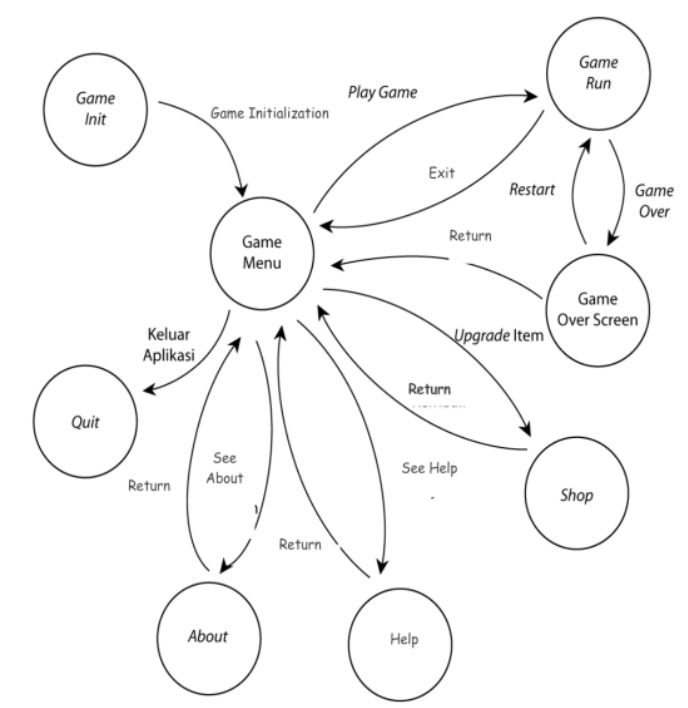

Gameplay

Figure 1. Menus Flow

In this game, players are required to form chemical bonds based on the atoms of their constituent elements. In each level there is a mission to form certain chemical bonds, which must be completed so that the next level can be opened. Before playing, players get a mission in the form of compounds that must be made. Players also get an explanation of the compounds in the mission. The names of compounds that must be made are mentioned in different naming rules at each level

At a certain level the player is given more than 1. ammunition atoms. In such cases the player must change the ammunition atom to the appropriate atom so that when fired at the target it can form chemical bonds. At certain times there is a falling star and the player must shoot the star to get it.

Actors Design

In this game there are 3 main actors who have different roles and functions, namely ammunition atoms, target atoms, and coins.

\section{Atomic ammunition}

This is the main actor played by players. Ammo atoms are fired at the target atom with the aim of forming a chemical bond. Ammunition is fired through a slingshot where the player can adjust the direction 
and strength of the shot so that it hits the target correctly. Ammo atoms have different atomic codes depending on the level being played.

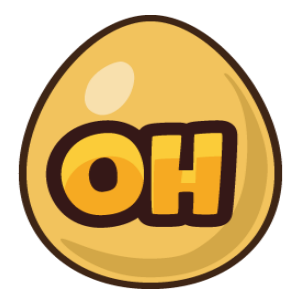

Figure 2. Texture design of ammunition actor

\section{Target Atom}

Atomic targets are actors who are targeted by ammunition atoms fired by players. If the player shoots the right ammo atom in the direction of the target atom, the bond and score increase. However, if the player fires ammunition atoms that are not right at the target, the lives of the players will be reduced.

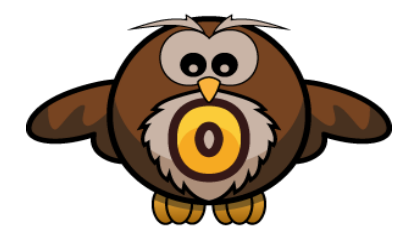

Figure 3. Texture Design of target atom

\section{Star}

Characters in the game that when shot using ammunition atoms will increase the number of stars from the player. This total star can later be used to buy or upgrade items in the game so that the game becomes more fun to play.

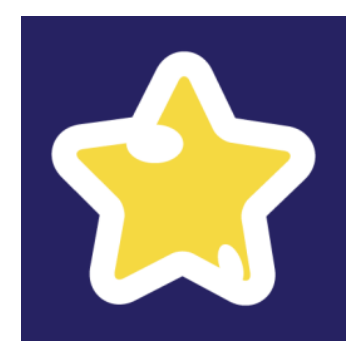

Figure 4. texture design of star

\section{Level Design}

There are 5 levels in this game that require players to form different chemical bonds. Difficulty parameters used are compounds and the number of compounds that must be formed, the number of target atoms and the speed of the target atoms.

1. Level 1

At this first level, to complete the game and move on to the next level, players must complete the following missions:
- Forming 2 Sodium Chloride compounds

- Collect 4 stars

While the atoms that are available in the level are as follows:

Table 1. Design of Level 1

\begin{tabular}{|c|c|}
\hline & Description \\
\hline \multirow{2}{*}{ Ammunition } & Hydrogen \\
\hline & Sodium \\
\hline Target & - Lithium \\
\hline & - Klor \\
\hline & - Magnesium \\
\hline & - Bromin \\
\hline & - $\quad$ Fluor \\
\hline & - Nitrogen \\
\hline
\end{tabular}

2. Level 2

At this level, to complete the game and move on to the next level, players must complete the following missions:

- Forming 2 compounds of Hydrogen Fluoride / Hydrofluoric Acid

- Collect 5 stars While the atoms that are available in the level are as follows:

Table 2. Desain Level 2

\begin{tabular}{ll}
\hline \multicolumn{1}{c}{ Actors } & \multicolumn{1}{c}{ Description } \\
\hline Ammunitions & $\begin{array}{r}\text { Hydrogen } \\
\text { Targets }\end{array}$ \\
& Hydroxide \\
& - Fluoride \\
& - Chlorine \\
& - Magnesium \\
& - Nickel \\
& - Fluoride \\
& - Nitrogen \\
& - Iodine \\
\hline
\end{tabular}


3. Level 3

At this level, to complete the game and move on to the next level, players must complete the following missions:

- Form 2 base compounds

- Collect 4 stars

While the atoms that are available in the level are as follows:

Table 3. Design of Level 3

\begin{tabular}{lll}
\hline \multicolumn{1}{c}{ Actors } & & Desciption \\
\hline Ammunitions & - & Hydrogen \\
Target & - & Sodium \\
& - & - hydroxide \\
& - & - Potassium \\
& - & - Sodium \\
& - & - Manganese \\
& - & - Fluorine \\
& - & - Chlorine \\
& - & - Nitrogen
\end{tabular}

\section{Level 4}

At this level, to complete the game and move on to the next level, players must complete the following missions:

- Forming 2 sodium hydroxide compounds

- Collect 4 stars

While the atoms that are available in the level are as follows:

Table 4. Design of Level 4

\begin{tabular}{ll}
\hline \multicolumn{1}{c}{ Actors } & \multicolumn{2}{c}{ Description } \\
\hline Ammunition & Hydrogen \\
Target & Hydroxyde \\
& - Lithium \\
& - Chlorine \\
& - Magnesium \\
& - Nickel \\
& - Fluorine \\
& - Nitrogen \\
& - Potassium \\
& - Calcium \\
\hline
\end{tabular}

\section{Level 5}

At this level, to complete the game and move on to the next level, players must complete the following missions:
- Forms 2 potassium hydroxide compounds

- Form 2 acid compounds

- Collect 3 stars While the atoms that are available in the level are as follows:

Table 5. Design of Level 5

\begin{tabular}{ll}
\hline \multicolumn{1}{c}{ Actors } & Description \\
\hline Ammunitions & - Hydrogen \\
Target & - Potassium \\
& - Hydroxide \\
& - Chlorine \\
& - Sodium \\
& - Iron \\
& - Fluoride \\
& - Iodine \\
& - Aluminum \\
& - Brimstone \\
& - Magnesium \\
\hline
\end{tabular}

\section{Result}

Device Testing

In this section, tests on application performance are carried out through device testing and the calculation of average FPS (frames per second) obtained on each device. Trials are carried out on the following devices:

1. Asus Zenfone C (ZC451)

- Specification

- Operating System: Android OS v4.4.2

- CPU: Intel Atom Z2520 Dual Core $1.2 \mathrm{GHz}$

- Screen: 480 x 854 pixels, 4.5 inches

2. Samsung Galaxy Core (I8262)

- Specification

- Operating System: Android OS v4.1.2

- CPU: Snapdragon MSM8225 Dual Core $1.2 \mathrm{GHz}$

- Screen: 480 x 854 pixels, 4.3 inches

3. Sony Xperia Miro (ST23i)

- Specification

- Operating System: Android OS v4.0.4

- CPU: Qualcomm MSM7225A 800 $\mathrm{MHz}$

- Screen: 320 x 480 pixels, 3.5 inches 
Table 6. Device of Result Testing

\begin{tabular}{lccc}
\hline $\begin{array}{c}\text { Parame } \\
\text { ter }\end{array}$ & Device 1 & Device 2 & Device 3 \\
\hline Perfor & GPU & GPU & GPU \\
mance & PowerVR & Adreno & Adreno \\
& SGX544M & 203,245 & 200,128 \\
& P2, 533 & MHz & MHz \\
& MHz & & \\
& $60 \mathrm{FPS}$ & $60 \mathrm{FPS}$ & $58 \mathrm{FPS}$ \\
Compat & OS & OS & OS \\
ibility & Android & Android & Android \\
& v4.4.2 & v4.1.2 & v4.0.4 \\
& Running & Running & Running \\
Resolut & $480 \times 854$ & $480 \times 854$ & $480 \times 320$ \\
ion & pixels & pixels & pixels \\
& Running & Running & Running \\
\hline
\end{tabular}

\section{User Testing}

After analyzing the device testing, then also testing the users who can judge whether this game is feasible to be released to the wider community. Data samples were taken from questionnaires given to 20 people with an average age of 18-22 years. The results of this testing are shown in table 6.

Table 7. Result of User Testing

\begin{tabular}{cccll}
$\begin{array}{c}\text { Comf } \\
\text { ortab } \\
\text { le }\end{array}$ & $\begin{array}{c}\text { User } \\
\text { Experi } \\
\text { ence }\end{array}$ & $\begin{array}{c}\text { Difficu } \\
\text { It }\end{array}$ & $\begin{array}{c}\text { Lesson } \\
\text { Giving }\end{array}$ & $\begin{array}{c}\text { Educat } \\
\text { ion } \\
\text { Media }\end{array}$ \\
\hline No. & Yes & Yes, 1 & Yes & Yes \\
Yes & Yes & No, 2 & No & No \\
No. & Yes & No, 1 & Yes & No \\
Yes & Yes & No, 2 & Yes & Yes \\
No. & Yes & Yes, 1 & No & No \\
Yes & Yes & No, 1 & No & No \\
Yes & Yes & Yes, 1 & No & No \\
Yes & Yes & Yes, 1 & No & Yes \\
Yes & Yes & Yes, 1 & Yes & Yes \\
Yes & Yes & No, 1 & No & No \\
Yes & Yes & No, 1 & Yes & Yes \\
No. & Yes & Yes, 1 & Yes & No \\
Yes & Yes & No, 2 & No & No
\end{tabular}

\begin{tabular}{ccclc}
\hline $\begin{array}{c}\text { Comf } \\
\text { ortab } \\
\text { le }\end{array}$ & $\begin{array}{c}\text { User } \\
\text { Experi } \\
\text { ence }\end{array}$ & $\begin{array}{c}\text { Difficu } \\
\text { It }\end{array}$ & $\begin{array}{c}\text { Lesson } \\
\text { Giving }\end{array}$ & $\begin{array}{c}\text { Educat } \\
\text { ion } \\
\text { Media }\end{array}$ \\
\hline Yes & Yes & No, 2 & Yes & Yes \\
Yes & Yes & Yes, 1 & Yes & Yes \\
No. & No. & No, 1 & Yes & Yes \\
Yes & Yes & No, 2 & No & No \\
No. & Yes & No, 1 & Yes & Yes \\
Yes & Yes & Yes, 1 & Yes & No \\
Yes & Yes & Yes, 1 & No & No \\
\hline
\end{tabular}

\section{Discussion}

From Table 6, it was found that the game's performance went well on all devices. This can be seen from the average FPS (frames per second) obtained from all devices. All features of the game run well on all devices. For operating system compatibility, the game can be run on Android v4.0 (KitKat) or ATS. For resolution, on device 1 and device 2 it works fine, but on device 3 that has a small screen resolution, there is little discrepancy between the height and width of the object to be desired.

From Table 7, the following questionnaire results are obtained, $70 \%$ of users feel comfortable when playing the game. As many as $95 \%$ stated that the application is easy to use and user-friendly. For gameplay difficulties, only $40 \%$ of users state that the game is difficult to play. In the first try, only $25 \%$ of respondents were able to complete level 1 and continue to level 2, while the other respondents lost at level 1 in the first try. For the delivery of material, $55 \%$ of users said the application added user insight. As for the last question, only $45 \%$ stated that the application is suitable for use in interactive learning media.

\section{Conclusion}

Based on the results of the analysis and testing, the following conclusions can be concluded: 
1. After this research has been made, this application cannot be used as a chemical bond learning medium because only $45 \%$ of respondents state that the application can be used as an alternative learning media.

2. Not responsive to touch on some parts and swipe problems when replacing ammunition atoms cause this research still needs to be fixed again to be ready for release to the public. $30 \%$ of respondents also stated this problem.

3. For a game, the gameplay of this application is quite difficult to play. This was obtained from $40 \%$ of respondents who stated that this game was difficult to play and only $25 \%$ of users could reach level 2 on the first try.

\section{References}

[1] Mulyasa. (2006). Becoming a Professional Teacher Creates Creative and Enjoyable Learning. Bandung: Publisher PT Remaja Rosdakarya.

[2] Law No. 20 of 2003 concerning the National Education System. Jakarta

[3] Dahar, Ratna Willis. 2006. Learning and Learning Theories. Erlangga, Jakarta;

[4] Mu'in, Fatchul. (2012). Character building; Theoretical Construction \& Practice. Jogjakarta: Ar RuzzMedia, p. 21;

[5] Masitoh, dkk. (2009). Kindergarten Learning Strategy. Surakarta: Universitas Terbuka.

[6] Narwati, Sri. 2011. Creative Learning: Tips for Becoming a Creative and Favorite Teacher. Yogyakarta: Familia.

[7] Nyimas Ariny Sabilarrusyda, Achmad Basuki, Kholid Fathoni, "Game Mobile Application History of Uthman Ibn Affan Based on Monotone Chain Convex Hull
Algorithm", IEEE International Electronics Symposium (IES), 2017.

[8] David Fahmi Abdillah, Kholid Fathoni, Fahim Nur Cahya Bagar, "First Person Shooter VR based Game On 10 November 1945 With Motion Controller", IEEE International Electronics Symposium (IES), 2018.

[9] Kholid Fathoni, Moh. Zikky, Anita Sri Nurhayati, "Application of KNearest Neighbor Algorithm For Puzzle Game of Human Body's System Learning on Virtual Mannequin", IEEE International Conference on Applied Science and Technology (iCAST), 2018.

[10] Istighotsah, Annisa U. "Design 'Chomical': Tower Defense Game by Implementing Chemical Experiments Using the LibGDX Framework," Teknik Informatika, Fakultas Teknologi Informasi, ITS. 2013.

[11] Prasetyo, Yogo D. "Brainchemist: Mobile Games as High School Learning Media in acid-base material, braking solutions and salt hydrolysis ". Universitas Negeri Yogyakarta. 2012.

[12] https://id.wikipedia.org/wiki/Ikatan_ kimia 